\title{
The Janus faces of bicarbonate therapy in the ICU: not sure!
}

\author{
Lui G. Forni ${ }^{1,2^{*}}$ (D, Luke E. Hodgson ${ }^{3}$ and Nicholas M. Selby ${ }^{4,5}$
}

๑ 2019 Springer-Verlag GmbH Germany, part of Springer Nature

Metabolic acidosis often complicates critical illness and is associated with poor outcomes [1]. However, there is often a failure to differentiate between cause of the acidosis and/or the effect of the metabolic disturbance and the mechanism(s) by which acidosis may cause such consequences are often unexplored [2]. Indeed, it is of fundamental importance that biochemical correction of any observed acidosis by whatever means must be coupled with correction of the underlying physiological disturbance. If one considers diabetic ketoacidosis for example, simple manipulation of the arterial $\mathrm{pH}$ will not address the underlying disturbance in glucose metabolism and indeed guidelines for the management do not support the use of alkali therapy. However, in the heterogenous critically ill population untangling the effects of the acidosis from those that arise because of the underlying condition is often a sisyphean task. Many clinical consequences of metabolic acidosis have been described, particularly with regard to the cardiovascular effects of severe metabolic acidaemia including myocardial dysfunction and vasopressor resistance [3-5]. The cardiovascular dysfunction observed appears to be $\mathrm{pH}$ dependent with an inevitable fall in cardiac output seen when the $\mathrm{pH}$ falls below 7.17.2 as well as a predisposition to ventricular arrhythmias. Correction of metabolic acidosis may have an observved positive inotropic effect which even extends to $\mathrm{pH}$ values above the normal physiological $\mathrm{pH}$ range although this will depend, in part, on the aetiology of the acidosis [6,7]. Altered mental state is often observed clinically in patients with acute metabolic acidosis, this is despite only minor changes in cerebrospinal and brain $\mathrm{pH}$ [8].

\footnotetext{
*Correspondence: luiforni@nhs.net

${ }^{1}$ The Royal Surrey County Hospital NHS Foundation Trust, Egerton Road, Guildford GU2 7XX, UK
}

Full author information is available at the end of the article
Of note, despite such clinical presentations, many of the observations are experimental with much of the quoted literature from animal studies, often non-mammalian, performed at $25-28{ }^{\circ} \mathrm{C}$ and at extremes of $\mathrm{pH}$ (often 6.8 or lower) [2]. Clinical studies focus solely on extracellular acidosis as it is easily measured and can be manipulated through exogenous means. Intracellular acidosis, on the other hand, is difficult to measure but of paramount importance to cellular function, particularly cardiac muscle cells [9].

Most discussions regarding metabolic acidosis focus on such negative effects. However, there are some that propose that the generation of an acidosis may have beneficial effects and confer a teleological advantage. Perhaps the most important observation supporting this view is the effect of acidosis on the oxyhaemoglobin dissociation curve of erythrocytes, first described by Bohr [10]. The oxyhaemoglobin dissociation curve is influenced by the local pH as well as $\mathrm{CO}_{2}$ levels. In areas of high $\mathrm{O}_{2}$ tension, $\mathrm{O}_{2}$ uptake is little affected by $\mathrm{pH}$ and the bound $\mathrm{CO}_{2}$ is readily off loaded. In areas of lower $\mathrm{O}_{2}$ tension the curve is "shifted to the right" in the presence of acidaemia increasing $\mathrm{O}_{2}$ extraction. This allows increased $\mathrm{O}_{2}$ delivery in areas where it is needed thereby matching local demand. This is observed in exercising muscle where local lactate and $\mathrm{CO}_{2}$ levels rise in concert with a lowering of $\mathrm{pH}$, thereby promoting $\mathrm{O}_{2}$ delivery and maintaining more efficient aerobic metabolism. Indeed, such effects on $\mathrm{O}_{2}$ delivery may be much more pronounced than any effects on cardiac output. For example, a decrease in $\mathrm{pH}$ from 7.4 to 7.2 that equates to an increase in hydrogen ion concentration of just $23 \mathrm{nmol} / \mathrm{l}$, results in an increase in $\mathrm{O}_{2}$ delivery that would otherwise require a $20 \%$ increase in cardiac output [2]. It could be argued therefore that we are adapted to survive physiological acidosis; hence intervening in a patient with metabolic acidosis without thought as to the potential physiological

\section{Springer}


consequences may potentially be inappropriate. For these reasons, the use of bicarbonate therapy in treating metabolic acidosis remains controversial. There are clinicians who are bicarbonate protagonists, supportive of its use and those who feel that bicarbonate therapy is of little benefit, being no more than a temporising action and at worst potentially harmful.

The principal objections to correcting acute metabolic acidosis with bicarbonate therapy include an increase in $\mathrm{PaCO}_{2}$ and hence increasing intracellular acidosis (socalled paradoxical acidosis), potential hypernatraemia and resulting hyperosmolar states, hypokalaemia and impairment in oxygen delivery. With regard to paradoxical acidosis, we appreciate that when sodium bicarbonate is added to a weakly acidic solution this generates $\mathrm{CO}_{2}$. Given there is no significant gradient between intracellular and extracellular $\mathrm{CO}_{2}$, the former rises in parallel and this results potentially in an intracellular acidosis. This has been demonstrated experimentally but in conditions so far removed from human physiology as to make the results inapplicable to clinical medicine [11]. However, if the in vitro experiments are repeated under conditions designed to simulate clinical practice, progressive intracellular alkalinisation rather than acidosis is observed [12]. Similarly, studies involving intact animals with imposed predetermined ventilatory restraints also differ significantly from the clinical situation with either a spontaneously breathing patient or one being mechanically ventilated with monitoring of the arterial blood gases and appropriate changes in ventilator settings [13]. Experimental studies have used a bicarbonate buffering system that approximates the 'closed' state, whereas in clinical practice it is almost fully 'open'. Under such conditions paradoxical acidosis is much less likely to occur, if at all.

The recent multicentre randomized trial, BICAR-ICU has reignited this debate about bicarbonate therapy [14]. No significant reduction in the primary composite outcome was observed, unsurprising given the study was powered to detect a $15 \%$ reduction in mortality. However, both a delay in the commencement of RRT as well as a reduction in the need for RRT was observed in patients with AKI (52-35\%, absolute difference estimate -16.7 (95\% CI - 26.4 to -7.0$), P=0.0009$ ), with a number needed to treat of only six. Such a meaningful patient centred outcome with significant health economic repercussions is of great interest. Moreover, a recent study using the MIMIC-III database reinforced this observation showing that the treatment of acute metabolic acidosis with sodium bicarbonate in patients with sepsis had no impact on the overall mortality but seems beneficial for those with coexistent AKI [15]. A recent scoping review highlighted the lack of data on the effects of intravenous sodium bicarbonate and called for further studies [16]. Before widespread adoption of alkali therapy in such patients it is worth considering that there are some significant limitations. The study was unblinded with $24 \%$ of patients in the control group receiving bicarbonate therapy, although blinding in this study would have been difficult given the regularity in which blood gases are drawn in ICU patients. Furthermore, all patients with metabolic acidosis were considered, without reference to different underlying aetiologies and as outlined, it is possible that potential benefit from bicarbonate replacement may be related to the cause of the metabolic disturbance.

So, what does this study tell us? Little with regard to further mechanistic insights as to the effects of acidosis, which is no surprise given the complex interactions involved within the patient as a whole. But it is hypothesis generating in that patients with metabolic acidosis and moderate to severe AKI, bicarbonate therapy may improve outcomes and reduce the requirement for RRT. This observation may reflect a reduction in the incidence of hyperkalaemia as well as other predefined indications for RRT through bicarbonate therapy. This does beg the question that RRT may not be necessary in some of these individuals as it may be viewed as little more than a mechanism by which bicarbonate is given in a controlled fashion. Furthermore, the results may identify individuals who can accommodate the higher osmolality and electrolyte swings associated with bicarbonate therapy an effect negated by renal replacement therapy (RRT).

At present, no robust recommendations can be given regarding the use of sodium bicarbonate to correct metabolic acidosis. The basic tenant remains that the underlying cause of the acidosis must be addressed. Clearly this rekindled interest in the use of alkali therapy is intriguing and further studies will be needed to confirm these findings. Particular interest should be focussed on patients with acute kidney injury and metabolic acidosis with stricter adherence to treatment protocols where possible (Table 1). Outcomes should include rates of RRT as well as mortality as outlined in the Table. Until these questions are answered then Janus will keep the doors open for bicarbonate therapy. For now. 
Table 1 PICOR design

\begin{tabular}{|c|c|c|}
\hline PICOT parameter & Description of parameter & Rationale \\
\hline Patient/population & $\begin{array}{l}\text { Eligibility: (1) Adult, (2) AKI KIDIGO stage 2/3, (3) } \\
\text { Metabolic acidosis ( } \mathrm{pH}<7.25, \mathrm{PaCO}_{2}<6.0 \mathrm{kPa} \text { and } \\
\left.\mathrm{HCO}_{3} \leq 20 \mathrm{mmol} / \mathrm{I}\right),(4)<48 \mathrm{~h} \text { of } \mathrm{ICU} \text { admission } \\
\text { Exclusions: single respiratory disorder, acute diarrhoea, } \\
\text { ileostomy or biliary drainage, stage } 4 \mathrm{CKD} \text { or chronic } \\
\text { dialysis, known RTA, DKA, high anion gap acids poison- } \\
\text { ing (e.g. aspirin, methanol), pregnancy, hypocalcaemia, } \\
\text { clinical decision in place to start RRT, death perceived as } \\
\text { imminent }\end{array}$ & $\begin{array}{l}\text { Jaber (2018) and Zhang (2018) both suggested benefit in patients } \\
\text { with metabolic acidosis and AKI (with no benefit seen in all- } \\
\text { comers) }\end{array}$ \\
\hline Intervention & IV NaHCO 3 titrated to achieve serum $\mathrm{pH}>7.3$ & $\begin{array}{l}\text { Routinely used formulation in clinical practice to replace } \mathrm{HCO}_{3} \text { rep- } \\
\text { licating a target } \mathrm{pH} \text { used in the Jaber study; represents a physi- } \\
\text { ologically plausible target in patients presenting with metabolic } \\
\text { acidosis and AKI, in which renal dysfunction may be a significant } \\
\text { contributor to the acid-base derangement }\end{array}$ \\
\hline Outcome & Primary outcome 90-day mortality & $\begin{array}{l}\text { A primary outcome of mortality is patient centred in a high risk } \\
\text { group; Secondary outcomes would include need for RRT due to } \\
\text { cost, resources }\end{array}$ \\
\hline RCT design & Superiority & $\begin{array}{l}\text { Secondary outcomes-If non-inferior } \mathrm{HCO}_{3} \text { would be represent } \\
\text { cheaper and less resource intensive }\end{array}$ \\
\hline
\end{tabular}

CKD chronic kidney disease stage 4 (eGFR<30), DKA diabetic ketoacidosis, IV intravenous, KDIGO (kidney disease improving global outcomes) stage 2 doubling baseline serum creatinine or urine output $<0.5 \mathrm{ml} / \mathrm{kg}$ for $\geq 12 \mathrm{~h}, \mathrm{NaHCO}_{3}$ sodium bicarbonate, $R R T$ renal replacement therapy, $R T A$ renal tubular acidosis

\section{Author details}

1 The Royal Surrey County Hospital NHS Foundation Trust, Egerton Road, Guildford GU2 7XX, UK. ${ }^{2}$ Faculty of Health and Medical Sciences, Department of Clinical and Experimental Medicine, University of Surrey, Guildford, Surrey GU2 7XH, UK. ${ }^{3}$ Western Sussex Hospitals NHS Foundation Trust, Anaesthetics Department, Worthing Hospital, Lyndhurst Rd, Worthing BN11 2DH, UK.

${ }^{4}$ Centre for Kidney Research and Innovation, School of Medicine, University of Nottingham, Nottingham, UK. ${ }^{5}$ Department of Renal Medicine, University Hospitals of Derby and Burton NHS Foundation Trust, Derby, UK.

\section{Compliance with Ethical Statement}

\section{Conflict of interest}

The authors report no conflict of interest regarding this manuscript.

\section{Publisher's Note}

Springer Nature remains neutral with regard to jurisdictional claims in published maps and institutional affiliations.

Received: 10 August 2019 Accepted: 27 November 2019 Published online: 9 December 2019

\section{References}

1. Jung B, Rimmele T, Le Goff C, Chanques G, Corne P, Jonquet $O$ et al (2011) Severe metabolic or mixed acidemia on intensive care unit admission: incidence, prognosis and administration of buffer therapy. A prospective, multiple-center study. Crit Care 15(5):R238

2. Handy JM, Soni N (2008) Physiological effects of hyperchloraemia and acidosis. Br J Anaesth 101(2):141-150

3. Berger DS, Fellner SK, Robinson KA, Vlasica K, Godoy IE, Shroff SG (1999) Disparate effects of three types of extracellular acidosis on left ventricular function. Am J Physiol 276(2):H582-H594
4. Otter D, Austin C (2000) Simultaneous monitoring of vascular contractility, intracellular $\mathrm{pH}$ and intracellular calcium in isolated rat mesenteric arteries; effects of weak bases. Exp Physiol 85(3):349-351

5. Levy B, Collin S, Sennoun N, Ducrocq N, Kimmoun A, Asfar P (2010) Vascular hyporesponsiveness to vasopressors in septic shock: from bench to bedside. Intensive Care Med. 36(12):2019-2029

6. Narins RG, Cohen JJ (1987) Bicarbonate therapy for organic acidosis: the case for its continued use. Ann Intern Med 106(4):615-618

7. Fanconi S, Burger R, Ghelfi D, Uehlinger J, Arbenz U (1993) Hemodynamic effects of sodium bicarbonate in critically ill neonates. Intensive Care Med 19(2):65-69

8. Kraut JA, Madias NE (2010) Metabolic acidosis: pathophysiology, diagnosis and management. Nat Rev Nephrol 6(5):274-285

9. Poole-Wilson PA (1989) Regulation of intracellular $\mathrm{pH}$ in the myocardium; relevance to pathology. Mol Cell Biochem 89(2):151-155

10. Bohr CHK, Krogh A (1904) Ueber einen in biologischer bezeihung wichtigen einfluss, den die kohlen-saurespannung des blutes auf dessen sauerstoffbindung ubt. Skand Arch Physiol 16:402-412

11. Ritter JM, Doktor HS, Benjamin N (1990) Paradoxical effect of bicarbonate on cytoplasmic pH. Lancet 335(8700):1243-1246

12. Goldsmith DJ, Forni LG, Hilton PJ (1997) Bicarbonate therapy and intracellular acidosis. Clin Sci (Lond) 93(6):593-598

13. Graf H, Leach W, Arieff Al (1985) Evidence for a detrimental effect of bicarbonate therapy in hypoxic lactic acidosis. Science 227(4688):754-756

14. Jaber S, Paugam C, Futier E, Lefrant JY, Lasocki S, Lescot T et al (2018) Sodium bicarbonate therapy for patients with severe metabolic acidaemia in the intensive care unit (BICAR-ICU): a multicentre, open-label, randomised controlled, phase 3 trial. Lancet 392(10141):31-40

15. Zhang Z, Zhu C, Mo L, Hong Y (2018) Effectiveness of sodium bicarbonate infusion on mortality in septic patients with metabolic acidosis. Intensive Care Med 44(11):1888-1895

16. Fujii T, Udy A, Licari E, Romero L, Bellomo R (2019) Sodium bicarbonate therapy for critically ill patients with metabolic acidosis: a scoping and a systematic review. J Crit Care 51:184-191 